\title{
A Equation for Size Distribution of Precipitation Elements Based on the Normal Distribution of Liquid Water Content
}

\author{
By Yoshiharu Shiotsuki \\ Technical College of Yamaguchi University, Ube, Japan \\ (Manuscript received 1 March 1973, in revised form 1 November 1974)
}

\begin{abstract}
A equation of precipitation-element size distribution will be proposed in this paper. It is represented by the normal distribution of liquid water content per unit volume of air with size. The conventional distributions (e.g. Marshall-Palmer (1948) and Best (1950)) and the characteristic distributions observed and computed as reported in the writer's previous paper (Shiotsuki, 1974) are fitted by this equation. Furthermore, the melted drop-size distributions for snowflakes and graupels are also represented by such normal distribution.

The most usefulness of the proposed equation is that it is applicable to almost all kinds of size distribution of various types of precipitation. The new equation is determined by the space liquid water content $(M)$ and the mean diameter $(\bar{D})$ and the standard deviation of it $(\sigma)$ of the normal distribution of liquid water content. Thus the present equation also needs some parameters which may be dependent on precipitation type, as well as the conventional equations. But those three parameters of the present equation can be easily determined by observing the data of radar reflectivity $(Z)$, precipitation intensity $(R)$ and number flux of precipitation particles $(N)$.
\end{abstract}

\section{Introduction}

The writer took an interest in the distribution of liquid water content with drop size in the work of the previous paper (1974). The observed stationary or flat size distributions at Hitoyoshi are well characterized by the shift of the concentrated region of liquid water content as compared with the M-P distributions. Consequently the values of Do (median volume diameter) of the flat distributions increase. We can see directly this process by use of the ideal size distribution curve. The ideal size distribution was introduced under the assumption that a given total liquid water content to a unit volume of air would be allotted equally to each group of drops in a equally divided size interval. It is easy to know where the concentrated region of liquid water content is, by seeing the excess part of the observed $N_{D}$ (space number density) values in comparison with the ideal distribution. The family of the ideal distributions is illustrated in Fig. 1. That is to say, the ideal distribution could be expressed as

$$
N_{D}=A D^{-3} \quad(A: \text { constant })
$$

because the derivative of liquid water content $(M)$ to drop size, derived from Eq. 1, is constant, as shown in the following equation.

$$
\begin{aligned}
\frac{\partial}{\partial D} M & =\frac{\partial}{\partial D} \int_{0}^{D} \frac{\pi}{6} \rho D^{3} N_{D} d D \\
& =\frac{\partial}{\partial D} \int_{0}^{D} A D^{-3} \frac{\pi}{6} \rho D^{3} d D=\frac{\partial}{\partial D}(K D)=K
\end{aligned}
$$

where $K=\frac{\pi}{6} \rho A=$ const, $\rho$ : density of water. If it is assumed that the maximum diameter is independent on the liquid water content, proportional coefficient $A$ in Eq. (1) will be determined by giving the value of liquid water content and the maximum diameter $\left(D_{\max }\right)$.

$$
\begin{aligned}
M & =A \frac{\pi}{6} \rho D_{\max } \\
\therefore \quad A & =\frac{M}{D_{\max }} \frac{6}{\rho \pi}
\end{aligned}
$$




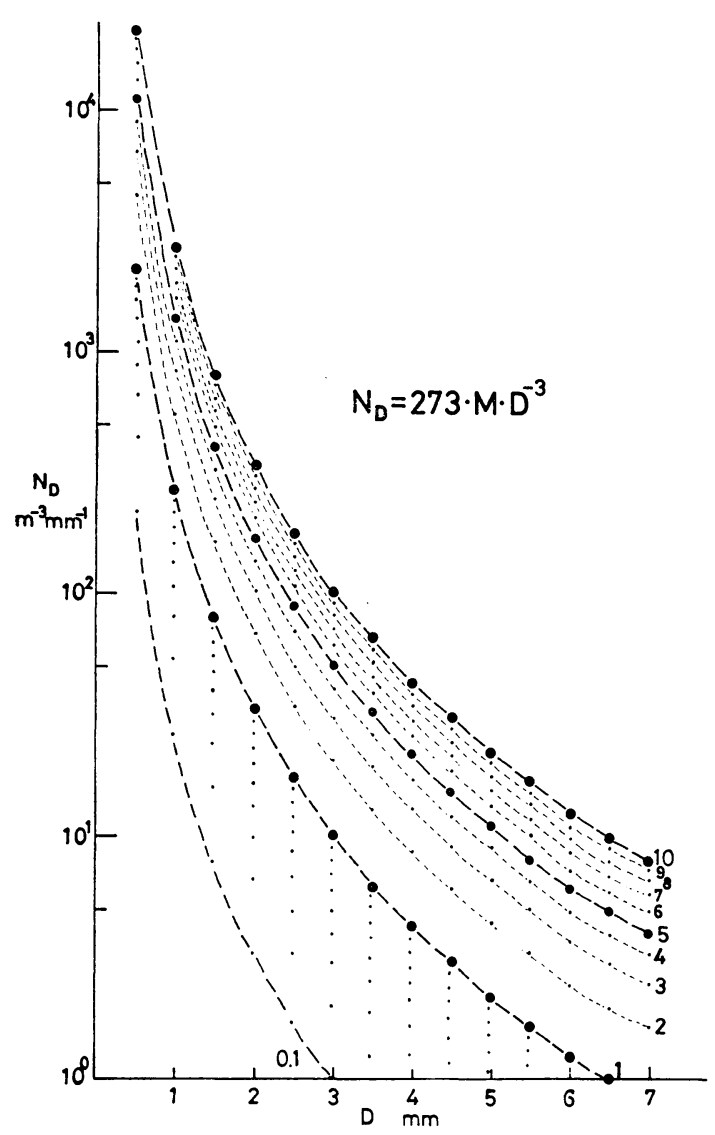

Fig. 1. The family of the ideal distribution $\left(N_{D}=273 M D^{-3} ; \quad N_{D}\right.$ in $\mathrm{m}^{-3} \mathrm{~mm}^{-1}$, $D$ in $\mathrm{mm}$, and $M$ in $\mathrm{g} / \mathrm{m}^{3}$ ). Affixed numbers to each curve show the values of $M$.

If for the maximum diameter is adopted the observed value of $7 \mathrm{~mm}$ at Hitoyoshi, and units of $M$, and $D_{\max }$ are given by $\mathrm{g} / \mathrm{m}^{3}$ and $\mathrm{mm}$, respectively,

$$
A=2.73 \times 10^{-7} M\left(\mathrm{~mm}^{-1}\right)
$$

Then, Eq (1) is $N_{D}=2.73 \times 10^{2} M D^{-3}$ ( $D:$ in $\mathrm{mm}$, and $N_{D}$ in $\mathrm{m}^{-3} \mathrm{~mm}^{-1}$ ). Therefore the observed distribution of which total liquid water content is $M$ can be evaluated by seeing the distribution of the ratio $m(D)$ of the observed number density $N_{D}$ to the ideal one, as

$$
m(D)=\left(N_{D}\right)_{o b s e r v e d} d D / \frac{6}{\rho \pi} M D^{-3}\left(d D / D_{\max }\right)
$$

Thus we can see the observed distribution of the liquid water with size not directly but relatively by use of the ideal distribution. From Eq. (5), $M m(D) d\left(D / D_{\max }\right)=\frac{\pi \rho}{6} D^{3} N_{D} d D$ represents the socalled probability density of liquid water of drops in size interval between $D$ and $D+d D$. And then the total liquid water content and the mean value of diameter can be calculated by the following equations.

$$
\begin{aligned}
& M=\int_{0}^{D_{\max }} \operatorname{Mm}(D)\left(d D / D_{\max }\right) \\
& \bar{D}=\int_{0}^{D_{\max }} \operatorname{Dm}(D)\left(d D / D_{\max }\right)
\end{aligned}
$$

Especially, when the $\left(N_{D}\right)_{\text {observed }}$ in Eq. (5) is the exponential type of $N_{0} e^{-\Lambda D}\left(N_{0}, \Lambda\right.$ : constant) for such distributions of Marshall \& Palmer and Gunn \& Marshall (1958), the distribution $m(D)$ may be destined to appear in the form of normal distribution. Because according to theoretical statistics, the Gamma distribution

$$
f(x: \alpha, \beta)=\left\{\alpha^{\beta} / \Gamma(\beta)\right\} \exp (-\alpha x) x^{\beta-1}
$$

( $x$ : variable, $\alpha, \beta$ : parameter)

approaches gradually to a normal distribution, when $\beta$ is large. The present $m(D) \propto D^{3} e^{-A D}$ may be in this case.

The purpose of this paper is to show that $m(D) / D_{\max }$ may obey to distribute in the form of the normal distribution for almost of the various types of drop-size distribution, of raindrop or snowflake and then the calculated rain or snow parameters are in good accordance with the observed data. A similar attempt was made and met with good results in the case of weak rainfall by Imai (1964). Moreover, in this report, derived various relationships between rain or snow parameters will be discussed, and convenient method to determine the drop-size distribution will be introduced.

\section{Examples of the normal distribution of liquid water content with drop-size}

\section{a) The case of the raindrop}

In calculating Eqs. (6) and (7), $\Delta D=0.5 \mathrm{~mm}$ and $D_{\max }=7 \mathrm{~mm}$ were adopted. And $m(D)$ was determined indirectly by use of the distribution of $M^{\prime}(D)$; the ratio of the observed $N_{D}$ to the $N_{D}$ of ideal distribution for $M=1 \mathrm{~g} / \mathrm{m}^{3}$. By use of Fig. 1, $M^{\prime}(D)$ may be simply and directly obtained by reading the value of the point in the 
families of $273 M D^{-3}$ curve, corresponding to the $N_{D}$ value. Otherwise $M^{\prime}(D)$ may be easily determined by calculating the ratio of the observed $N_{D}$ to the $N_{D}$ of the ideal distribution for $M=1$, as shown in Fig. 2. The $N_{D}$ values at $0.25,0.75$ .... $6.75 \mathrm{~mm}$ of diameter were taken as representative for the corresponding classes. So that the total number of class is 14 . In the analysis, the fall velocity of raindrop is given by the equation of Gunn \& Kinzer (1948).

Fig. 3 (a) and (b) show the results in the case of the observed stationary distributions at Hitoyoshi as described in the writer's previous paper. First, the observed distribution of number density, which is shown in the figure (a) by the histogram was transformed into the liquid water distribution by $M^{\prime}$ as shown in the figure (b),

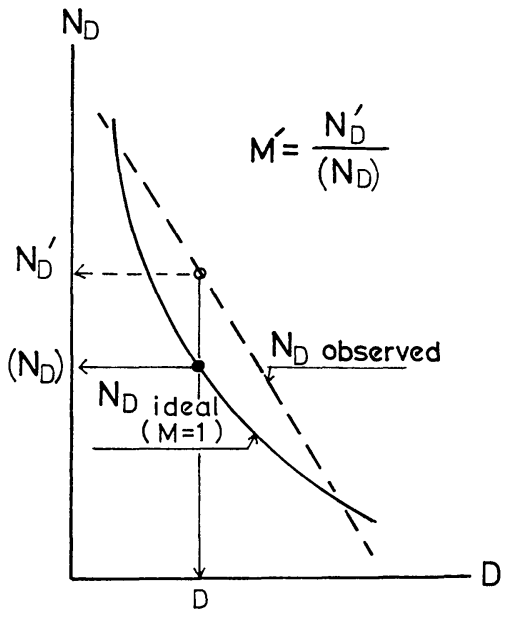

Fig. 2. Determination method of $M^{\prime}$ by use of Fig. 1 .

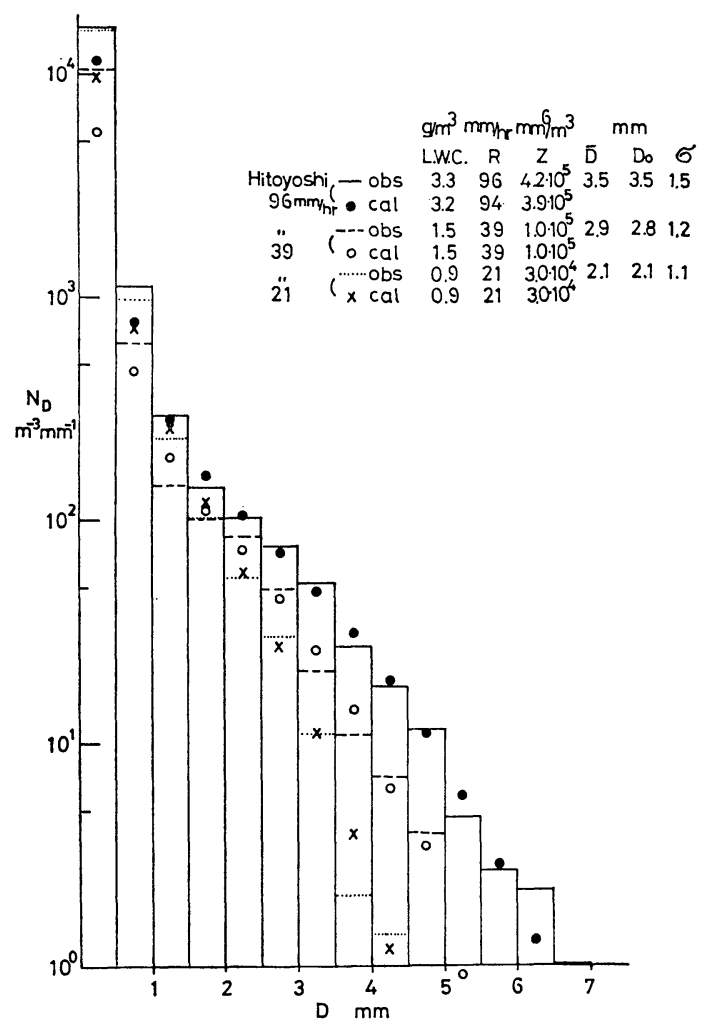

(a)
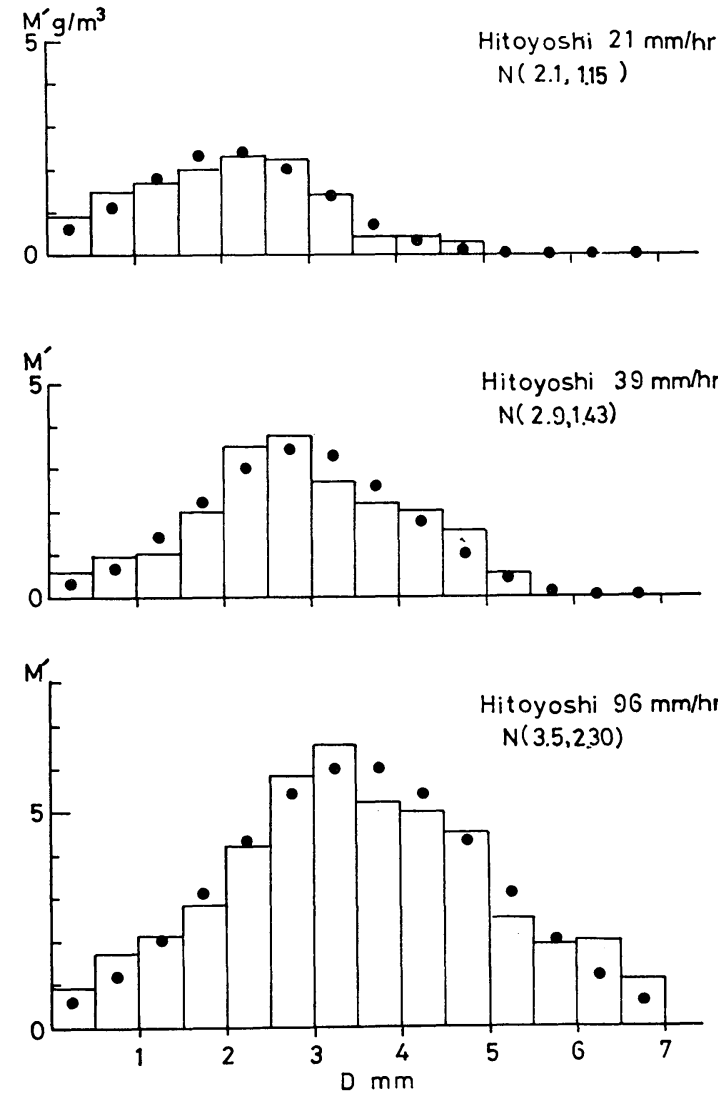

(b)

Fig. 3. Examples of the normalized drop-size distribution for the observed spectra at Hitoyoshi. The histogram and the plot of some symbols indicate the observed (obs.) and the normalized (cal.) distribution, respectively. The distribution of the number concentration of drops is shown in the figure (a), and the distribution of the liquid water content with size, $M^{\prime}$, is shown in the figure (b). Total liquid water content $M$ is shown by the letter of L.W.C. in this figure. 
using Fig. 1. Secondly, from the observed distribution of liquid water, the mean value of $D: \bar{D}(\mathrm{~mm})$, and the variance of $D: \sigma^{2}\left(\mathrm{~mm}^{2}\right)$, were calculated, and then the normal distribution $N\left(\bar{D}, \sigma^{2}\right)$ with those parameters would be obtained as shown in the figure (b). Of course, the obtained normal distribution is the truncated one between $D=0$ and $7 \mathrm{~mm}$. In the figure (a) the obtained $\bar{D}, \sigma$ and $D_{0}(\mathrm{~mm})$ are also indicated. Third, from the determined normal distribution, the distribution of number density, $\left\langle N_{D}\right\rangle$, was calcualted by

$$
\begin{aligned}
\left\langle N_{B}\right\rangle & =\frac{M}{D_{\max }} \frac{6}{\rho \pi} D^{-3} m(D) \\
& =\frac{6 M}{\rho \pi} D^{-3} \frac{m(D)}{D_{\max }} \\
& =\frac{6 M}{\rho \pi} D^{-3} \frac{1}{\sqrt{2 \pi} \sigma} e^{-\frac{(D-\bar{D})^{2}}{2 \sigma^{2}}}
\end{aligned}
$$

The obtained distribution, $\left\langle N_{D}\right\rangle$, is plotted by some symbols in the figure (a), in which the rain

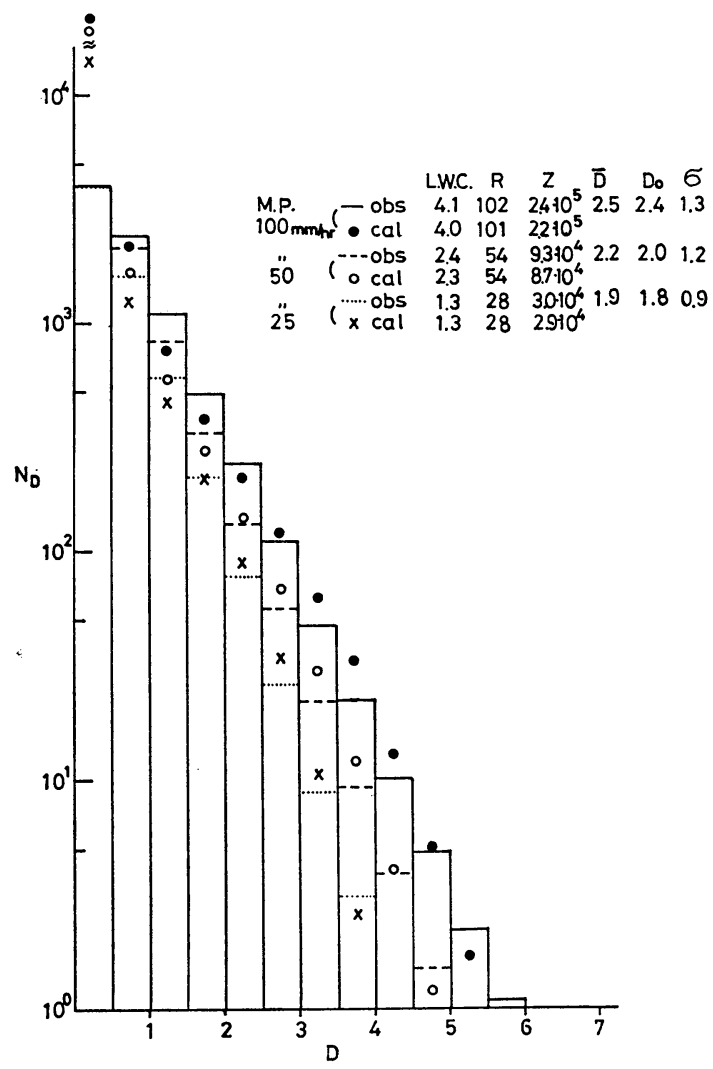

Fig. 4. The cases of the $M-P$ distribution, samely as Fig. 3. But the figure of the distribution of $M^{\prime}$ is not shown. parameters, from both of the observed and the calculated from Eq. (8), are also shown. Thus, the obtained distribution, and the derived parameters well represent and approximate to the observed one.

Other examples of normalizing by the similar procedures are shown in Fig. 4 and 5 . The former figure represents the results of application for the M-P type distributions and the latter includes the results for the computed distributions obtained in the writer's previous paper, and Best's distribution for $D_{0}=3.5 \mathrm{~mm}$. In application for Best's distribution, the equation $1-F=\exp$ $\left\{-(D / a)^{n}\right\}$ was transformed for convenience, as follows. As the variable $F$ in the equation $(a, n$ : the constants determined by rate of precipitation)

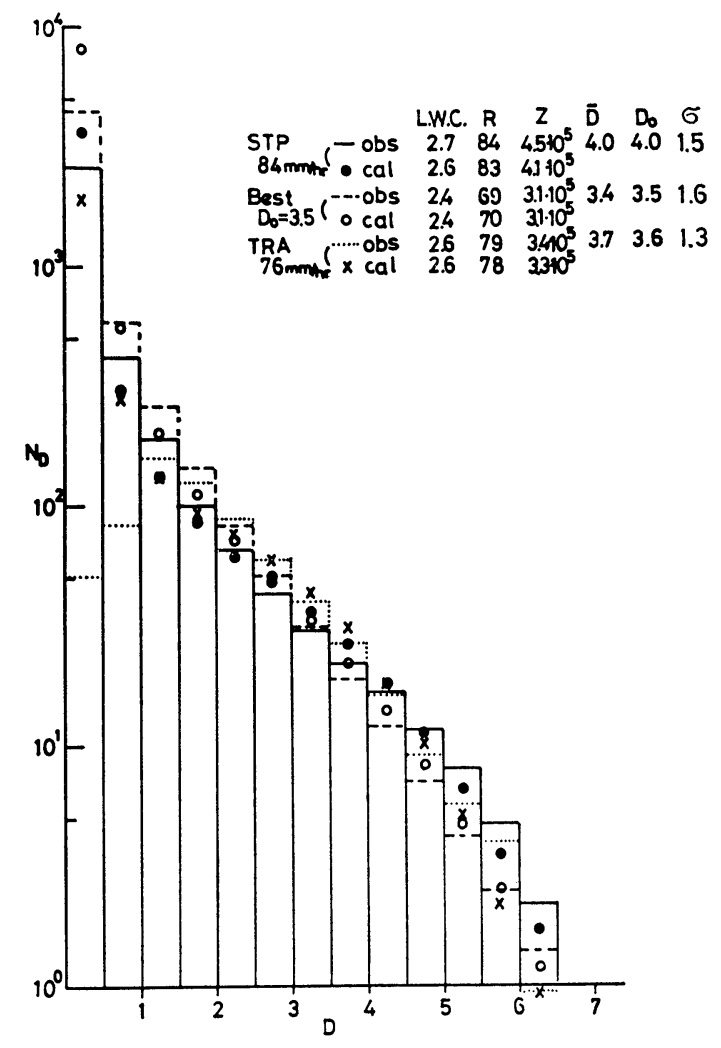

Fig. 5. Another cases, samely as Fig. 4. Where, Best $D_{0}=3.5$ is of the case of $D_{0}=3.5 \mathrm{~mm}$ of the Best distribution, and STP 84 and TRA 76 are of some cases of the computed distributions in the well mixed cloud and by the transport equation, respectively, under the stochastic processes as described in the writer's previous paper. 
represents the fraction of liquid water in the air comprised by drops with diameter less than $D$, we can easily obtain the relation $D_{0}=(0.69)^{1 / n} a$ by giving $F=1 / 2$. Therefore, $a=D_{0} \times(0.69)^{-1 / n}$, and the fraction of the liquid water content of the size interval $d D$ is be given by

$$
\frac{d F}{d D}=n \cdot 0.69 D_{0}^{-n} D^{n-1} \exp \left\{-0.69\left(D / D_{0}\right)^{n}\right\}
$$

Then we can obtain $d F / d D$ from Eq. (9), by giving the mean value of $n=2.25$ by Best, and the appropriate value of $D_{0}$.

As shown in Fig. 4 and 5, it is found that normalization may be applicable for various types of distribution. In fact, most of normalized distributions for other cases of Fig. 11 and Fig. 15 in the writer's previous paper, and also for each stage of computation of distribution of raindrops with the processes of coalescence and breakup, were well representative to the original distribution. It is fairly seen from the figures as shown above that all of the derived values of the rain parameters such as $M, R, Z$ and $D_{0}-\bar{D}$, are within $\pm 10 \%$ of the original one. Then we can say that almost all of the raindrop size distribution are represented by the normal distribution of liquid water content.

\section{b) The case of the melted drop from snowflake and graupel}

The same procedures as described above in the case of raindrop size distributions were applied to the size distributions of the melted drops from snowflake and graupel. Fig. 6 shows the results for the Gunn-Marshall distributions (Gunn and Marshall, 1958). Also in this case, the adaptability of the obtained normal distribution to the original (observed) distribution is well as revealed in the comparison of values of parameters $M, R, Z$ and ' $D_{0}-\bar{D}$. The calculated values are within $\pm 10 \%$ of the original one. In the analysis here, the terminal fall speed of snowflake was given by $v=300 D^{0.31}$ after Langleben (1954). Fig. 7 shows the results for each snowfall on Jan. 22, 1971, at Hikosan. The same fall speed equation as above was used, although the main snow crystals of each snowfall were different with each other such as HK 3.7: needle, HK 3.3: needle, HK 4.1: dendrite and HK 3.8: plate. As shown in Fig. 7 (b), in all cases the abundunt liquid water content is comprised in the size range of $0.5 \sim 1 \mathrm{~mm}$ diameter. This may be one of the characteristics of the

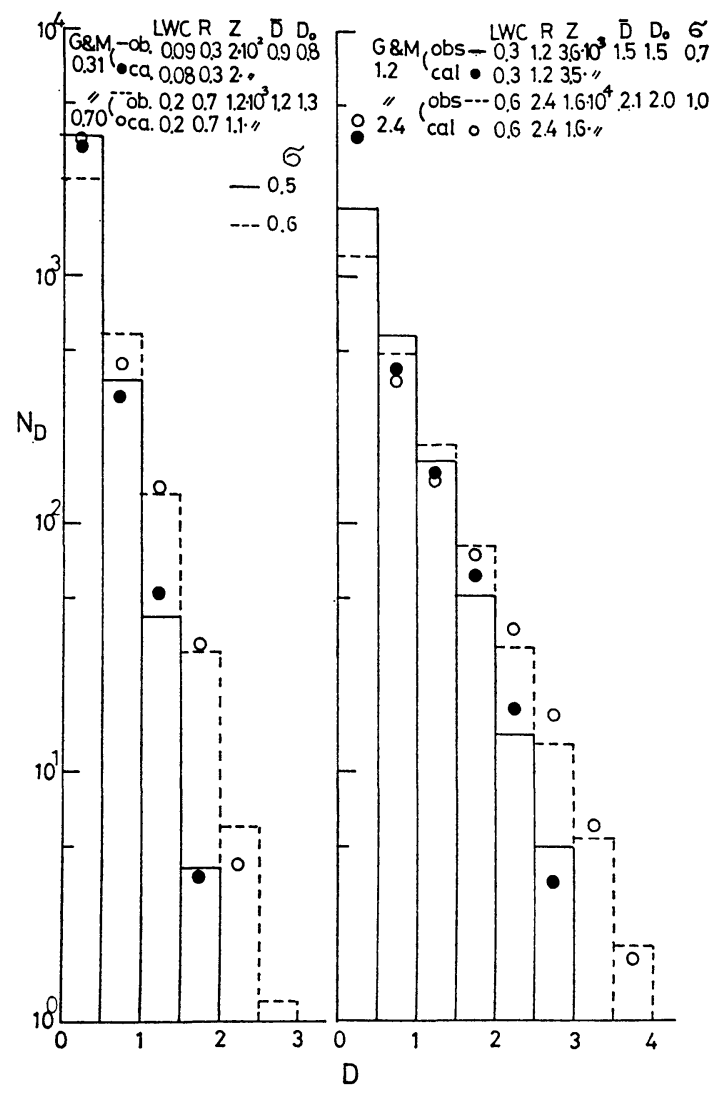

Fig. 6. The cases of the $G-M$ distribution for snowflake, samely as Fig. 4.

snowflake size distribution of the orographic snowfall at Hikosan. The normal distribution is also seemed to be applicable for the snowflakes observed at Hikosan, as far as seeing the good accordance of parameters.

The size distribution of graupels observed on the same day and at the same site as the snowflakes of Fig. 7 was analysed as shown in Fig. 8. The terminal fall speed of graupel was given by $v=650 \sqrt{D}$ proposed by Fujiwara, et al. (1972). The normal distribution is applicable also in this case.

Thus, as described above it can be said that the representation of the size distribution by the normal distribution of liquid water content with size is possible for not only the raindrop, but also the melted drop of snowflake and graupel.

\section{3. $\boldsymbol{\sigma}-\overline{\boldsymbol{D}}$ relation}

Normal distribution of liquid water content with drop-size is determined by the combination of the mean diameter $\bar{D}$ and the variance 


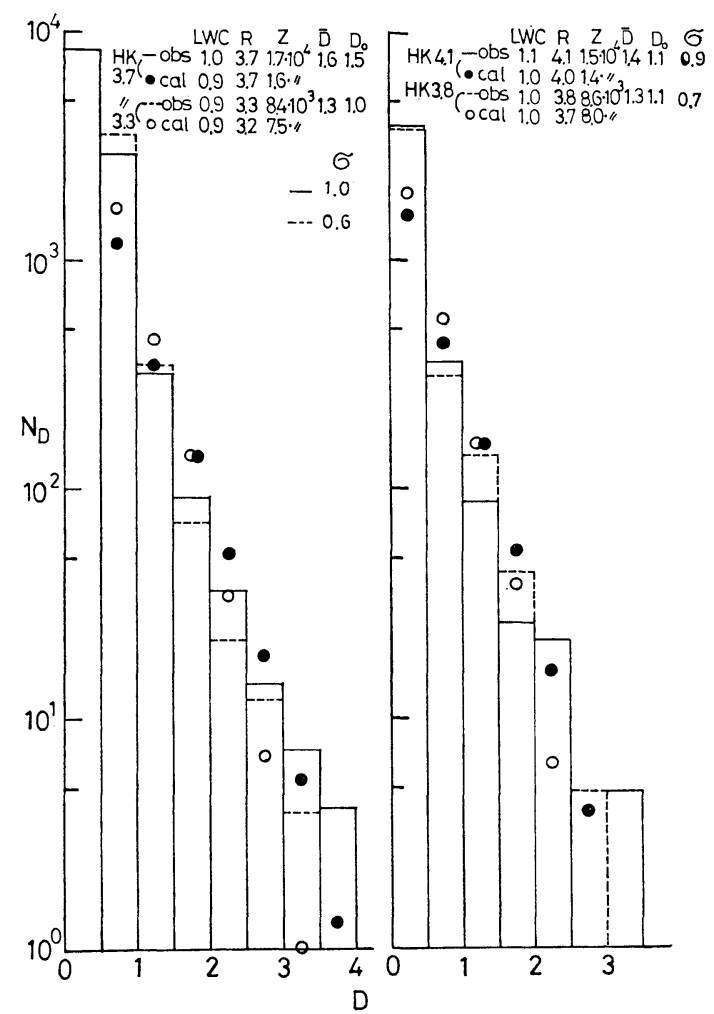

(a)

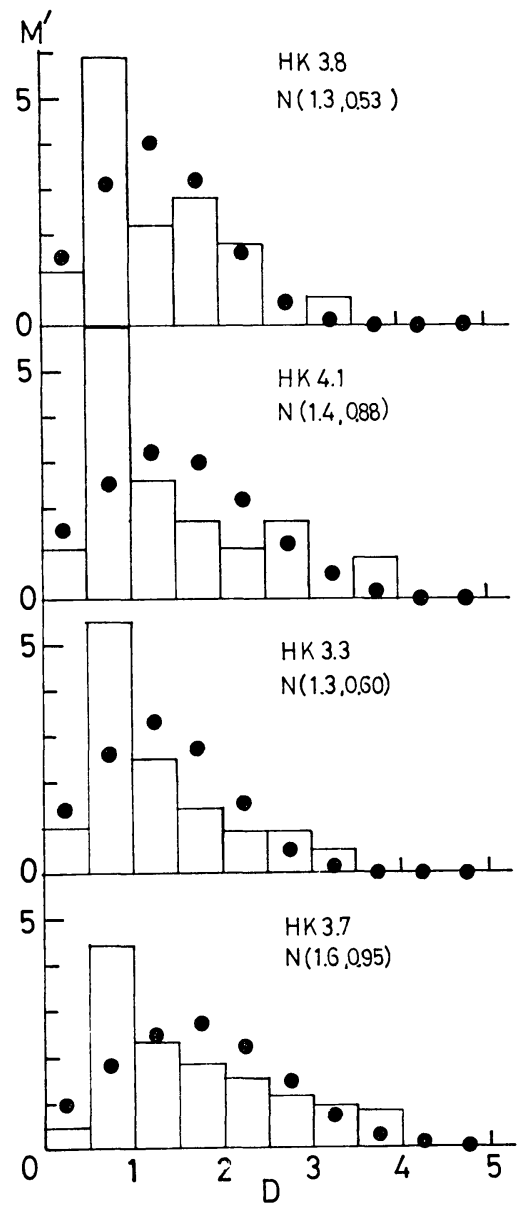

(b)

Fig. 7. The cases of the observed size distribution of melted drop of snowflakes at Mt. Hikosan, Kyushu, samely as Fig. 3.

$\sigma^{2}(\sigma:$ standard deviation of $\bar{D})$. As shown in the preceding section, $\bar{D}$ and $\sigma$ would be dependent on the type of precipitation. Both of $\bar{D}$ and $\sigma$ are small in the weak continuous rain where the M-P distribution is suitable and in the snowfall. On the other hand, they are large in the developed convective rain where the stationary distribution as Hitoyoshi's is fittable.

If we use $\infty$ instead of $D_{\max }$ in Eq. 7,

$$
\begin{aligned}
\bar{D} & =\int_{0}^{\infty} m(D) D\left(d D / D_{\text {max }}\right) \\
& =\int_{0}^{\infty} \frac{\rho \pi}{6} \frac{1}{M} D^{3}\left(N_{D}\right)_{\text {observed }} D d D \\
& =\frac{\int_{0}^{\infty}\left(N_{D}\right)_{\text {observed }} D^{4} d D}{\int_{0}^{\infty}\left(N_{D}\right)_{\text {observed }} D^{3} d D}
\end{aligned}
$$

will be derived.

And according to the same procedure as above,

$$
\begin{aligned}
\sigma^{2} & =\int_{0}^{\infty} m(D) D^{2}\left(d D / D_{\max }\right)-(\bar{D})^{2} \\
& =\frac{\int_{0}^{\infty}\left(N_{D}\right)_{\text {observed }} D^{5} d D}{\int_{0}^{\infty}\left(N_{D}\right)_{\text {observed }} D^{3} d D}-(\bar{D})^{2}
\end{aligned}
$$

From Eqs. 10 and 11 , we can estimate $\bar{D}$ and $\sigma$ theoretically when $N_{D}$ equation is expressed by the function of $D$. The equations which were hitherto reported by Marshall and Palmer (1948), Best (1950), Gunn and Marshall (1956), and Shiotsuki (1974) are applicable to this case. Table 1 shows the $\bar{D}-R, \sigma-R$ and $\sigma-\bar{D}$ relations obtained from these $N_{D}$ equations.

Fig. 9 shows the comparison between the 
Table 1. The obtained relationships of $\bar{D}-R, \sigma-R$ and $\sigma-\bar{D}$ when applying four $N_{D}$ equations hitherto reported to Eq. 10 and 11 .

\begin{tabular}{l|c|c|c|c}
\hline & $\left(N_{D}\right)_{\text {observed }}$ & $\bar{D}-R$ & $\sigma-R$ & $\sigma-\bar{D}$ \\
\hline Marshall \& Palmer & const. $\times e^{-41 R^{-0.21}}{ }_{D}$ & $\bar{D}=0.98 R^{0.21}$ & $\sigma=0.49 R^{0.21}$ & $\sigma=\frac{1}{2} \bar{D}$ \\
Best & const. $\times D^{n-4} e^{-\left(\frac{D}{a}\right)^{n}}$ & $\bar{D}=1.15 R^{0.23}$ & $\sigma=0.55 R^{0.23}$ & $\sigma=0.47 \bar{D}$ \\
Shiotsuki & const. $\times e^{-R^{-0.44} D}$ & $\bar{D}=1.33 R^{0.22}$ & $\sigma=0.48 R^{0.22}$ & $\sigma=0.36 \bar{D}$ \\
Gunn \& Marshall & const. $\times e^{-25.5 R^{-0.48}}{ }_{D}$ & $\bar{D}=1.57 R^{0.48}$ & $\sigma=0.78 R^{0.48}$ & $\sigma=\frac{1}{2} \bar{D}$ \\
\hline
\end{tabular}
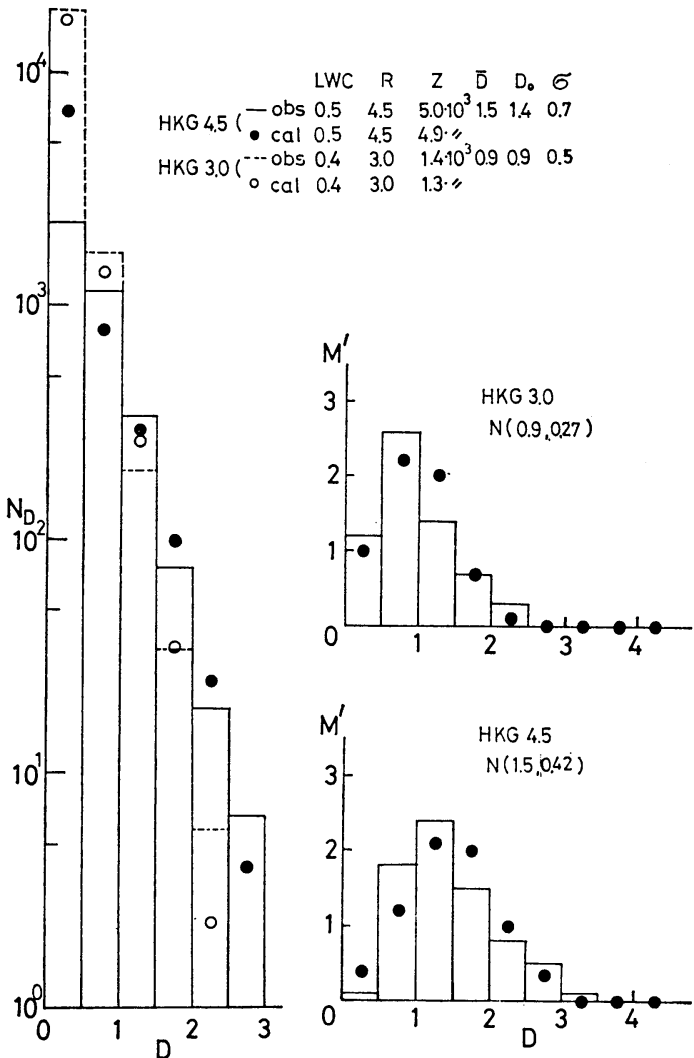

Fig. 8. The cases of the observed size distribution of melted drop of graupels at Mt. Hikosan, samely as Fig. 3.

distribution of $(\bar{D}, \sigma)$ point obtained in the preceding section, and three $\sigma-\bar{D}$ lines of Table 1 . It is seen that the obtained $\sigma-\bar{D}$ lines are representative for the points of various kinds of precipitation, corresponding to the evolution of size distribution.

At present, however, we do not know the means by which we can distinguish the type of precipita tion. Therefore it is not easy to choose directly the adequate $\sigma-\bar{D}$ equation which is suitable for

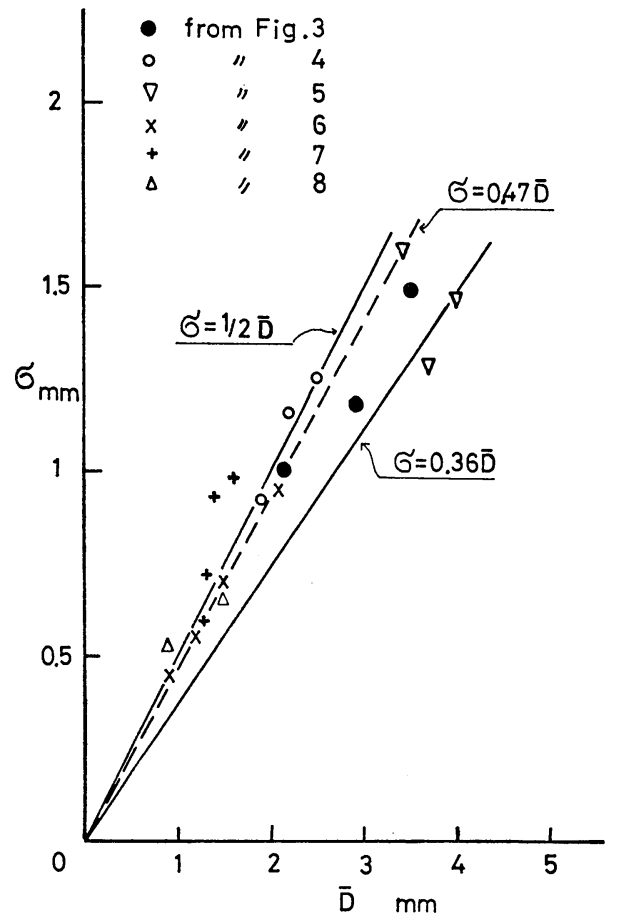

Fig. 9. Comparison of the obtained values of $\bar{D}$ and $\sigma$ from Figs. $3 \sim 7$ with three $\sigma-\bar{D}$ relation lines as exhibited in Table 1.

the precipitation. In the following section, a simple method to determine $\bar{D}$ and $\sigma$ will be introduced.

\section{Diagram}

We are frequently coming across the necessity to know the drop-size distritution of some precipitation echoes on the radar scope, for weather forcasting, precipitation measurements by radar, and so on. For those purposes, the parameter diagrams were made under the assumption of the drop-size range of $0 \sim 7 \mathrm{~mm}$ diameter as described in $\S 1$. Fig. 10 shows the diagrams 


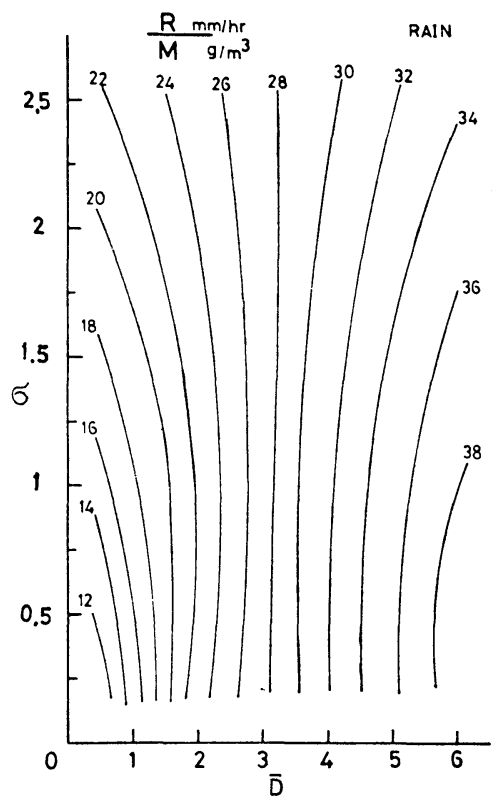

(a)

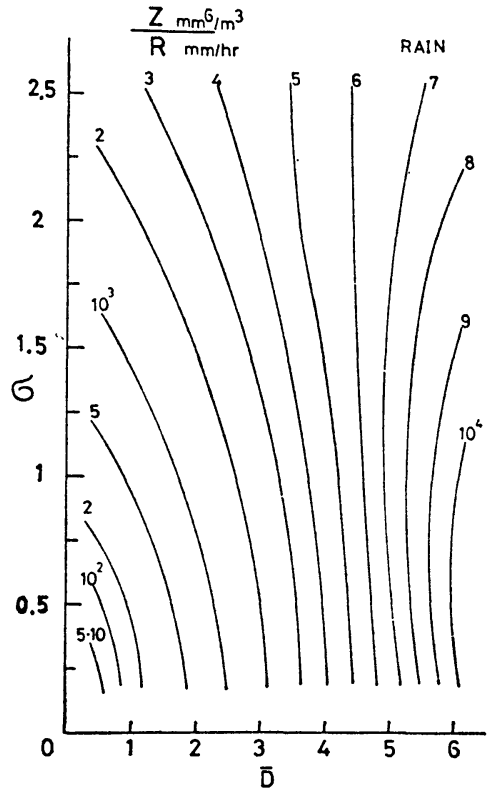

(c)

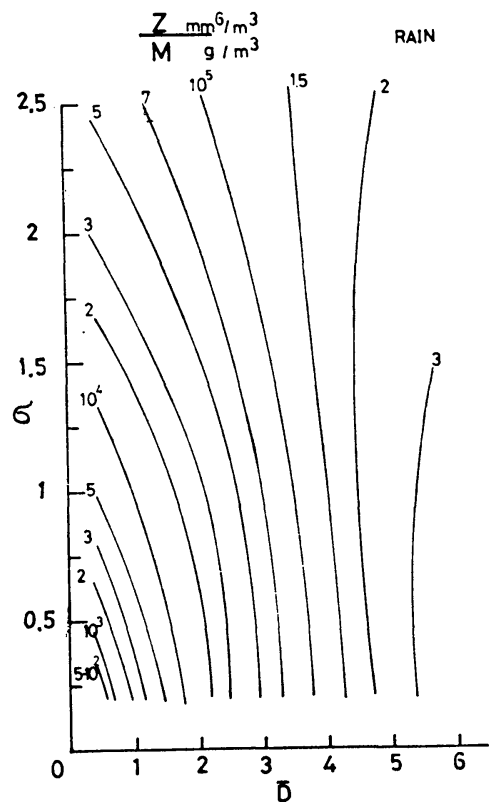

(b)

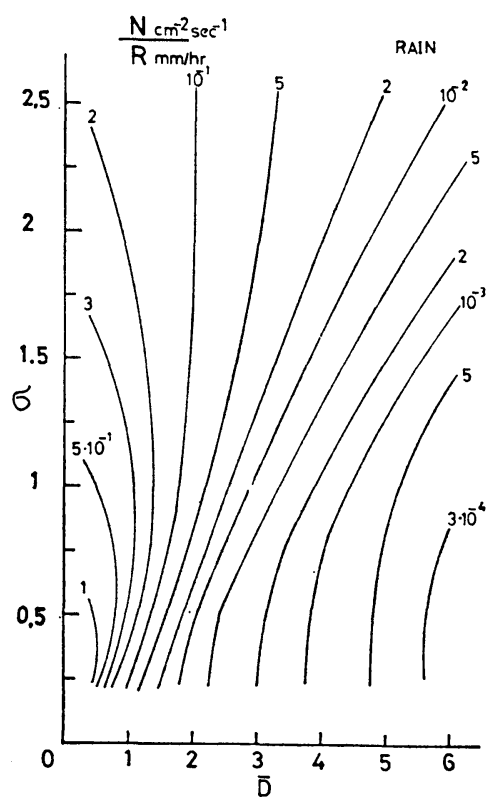

(d)

Fig. 10. Rain parameter diagram.

(a) Relation between $R, \sigma$ and $\bar{D}\left(\sim D_{0}\right)$ for present $N_{D}$ equation which is characterized by a truncated normal distribution of liquid water content, $N\left(\bar{D}, \sigma^{2}\right)$. The figure is drawn for the case of liquid water content $M=1 \mathrm{~g} / \mathrm{m}^{3}$.

(b) Relation between $Z, \sigma$ and $\bar{D}$ samely as (a).

(c) Relation between the ratio $Z / R, \sigma$ and $\bar{D}$. (independent of $M$ )

(d) Relation between the ratio $N / R, \sigma$ and $\bar{D}$. (independent of $M$ ) 
for raindrop. The similar diagrams for snowflake and graupel were made, but are not exhibited here.

In the diagrams, $Z, R, M$ and $N$ are the radar reflectivity $\left(\mathrm{mm}^{6} / \mathrm{m}^{3}\right)$, the precipitation rate $(\mathrm{mm} /$ $\mathrm{hr}$ ), the liquid water content $\left(\mathrm{g} / \mathrm{m}^{3}\right)$, and the number flux of precipitation particle (number $/ \mathrm{cm}^{2}$ sec), respectively. In other words, $N$ is the total count number of raindrop, snowflake, or graupel in the size range between 0 and $7 \mathrm{~mm}$ in diameter or melted diameter for the unit surface area and unit time. $N$ is calculated by the equation of

$$
N=\sum_{D=0.25}^{6.75} N_{D} v \Delta D \text {. }
$$

From the figures (a) and (b) of Fig. 10, we can know the value of $Z$ and $R$ when $M, \sigma$ and $\bar{D}$ are known, or reversely the value of $\sigma$ and $\bar{D}$ by knowing $M, R$ and $Z$. Ordinarily we can know the values of $R$ and $Z$ from the rain gauge network on the surface and by radar, respectively. If the estimate of liquid water content by some means is possible, the drop-size distribution could be determined by the obseved values of $Z, R$ and $M$.

On the other hand, in the figure (c), we may determine $Z / R$ independent on $M$ by knowing $\sigma$ and $\bar{D}$. Using a relationship between $\sigma$ and $\bar{D}$ according to the precipitation type, we can obtain either of both of $\sigma$ and $\bar{D}$ by knowing $Z / R$. This method nevertheless, seems not to be adequate enough for practice, because the $\sigma-\bar{D}$

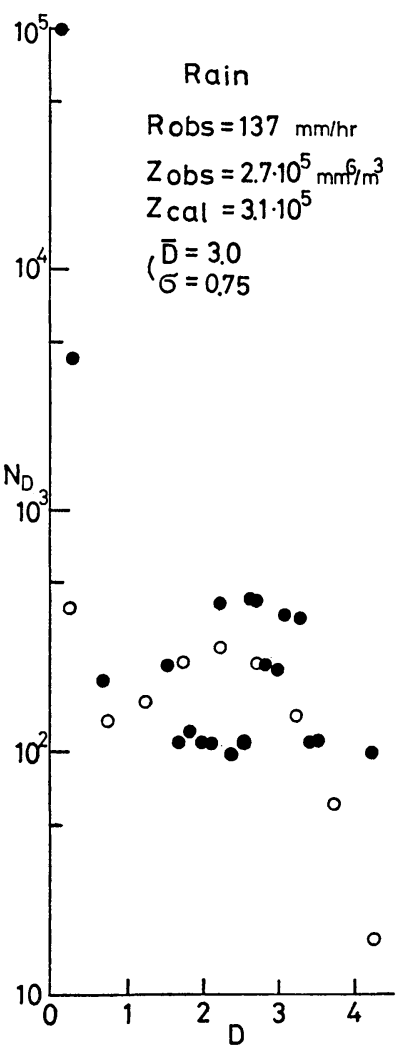

(a)

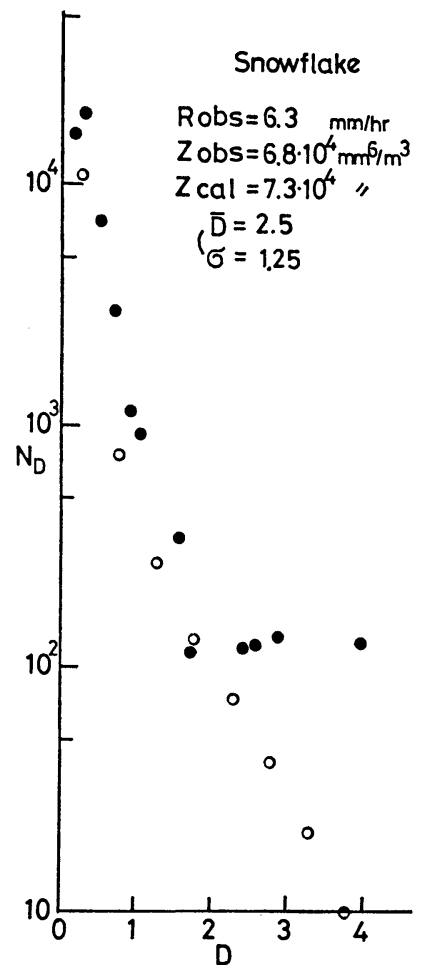

(b)

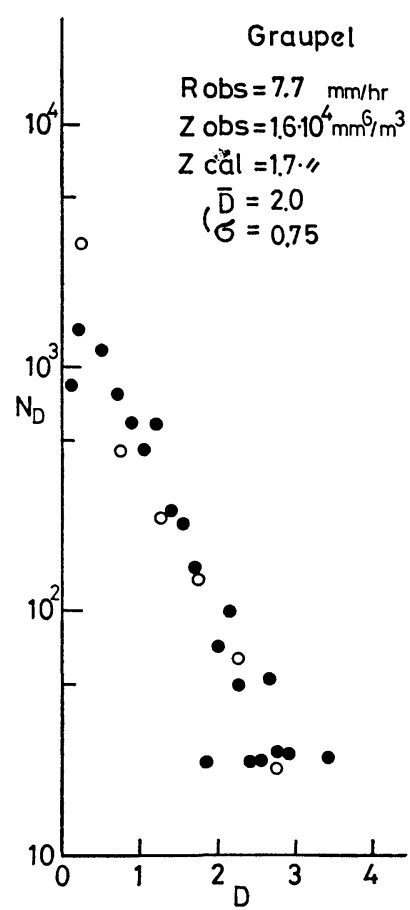

(c)

Fig. 11. Examples of the normalized drop-size distribution (plotted by $\bigcirc$ ) for the instantaneous distribution observed (plotted by $O$ ) in a precipitation, finding the parameters of $\sigma$, $\bar{D}$ and $M$ by knowing the parameters of $Z, R$ and $N$.

(a) for the case of instantaneous sampling in the developed convective rainfall at Hitoyoshi.

(b) for the case of instantaneous sampling of snowflakes in the snowfall at Mt. Hikosan.

(c) for the case of graupel, samely as (b). 
equation corresponding to prcipitation has not be established.

But we might have a simple method to determine $\sigma$ and $\bar{D}$ by use of another kind of parameter in addition to the parameters of $Z$ and $R$. If the number flux $N$ at the surface is observed by means of some method, this might be another parameter necessary for determination of $\sigma$ and $\bar{D}$. In Fig. 10 (d) the curves of the value of $N / R$ are depicted. $N / R$ is independent on $M$ as well as $Z / R$. $\sigma$ and $\bar{D}$ are easily determined by the intersection point of two curves of $Z / R$ and $N / R$. After determining $\sigma$ and $\bar{D}$, we can obtain the value of $M$ using either of the diagram of $Z / M$ and $R / M$. This method can be conveniently applied for determination of the drop-size distributions in both the averaged sample and the instantaneous samples for a precipitation.

Some examples of analysis by use of this method are shown in Fig. 11. (a) (c) are the results for the cases of instantaneous sampling during the rainfall at Hitoyoshi and the snowfall at Hikosan. In the procedures, the values of $Z$ and $R$ was applied by the values calculated directly from the drop-data of the fiter paper. As seen in the figures, the relative difference of $Z$ between the observed and the determined distribution is within $10 \%$.

Thus we can directly determine the drop-size distribution by obtaining three informations of the radar reflectivity, the precipitation rate, and the number flux. This method is convenient for determination of the drop-size distribution, because what we need is not the size of each drop, but only the total number of drops.

\section{Consideration}

As referred in the preceding sections, we could immediately determine the drop-size distribution and the various kinds of parameter, if the applicable $\sigma-\bar{D}$ relationship is established according to the type of precipitation which may be defined by some visible observation such as synoptical characteristics of precipitation cloud, radar echo type, and precipitation rate. In this section, moreover, a change of the combination of $\sigma$ and $\bar{D}$ according to the growth of precipitation will be discussed by use of the distributions obtained by numerical experiments in the writer's previous paper.

In Fig. 12 (a) and (b), the changes of $(\bar{D}, \sigma)$ points, which were obtained from the resulted distributions under the stochastic model are shown. In this case, as the rain parameters of $R, Z$ and $M$ were obtained formerly, the values of $R / M$ and $Z / M$ can be calculated easily. $\sigma$ and $\bar{D}$ are obtained from $R$ and $Z$ by using Fig. 10. The affixed number to the symbols in the figure shows the time in seconds from the beginning of computation. Because the size distribution becomes to a stationary type due to the drop coalescence and breakup, the point of $(\bar{D}, \sigma)$ tends to move apart from the $\sigma=\frac{1}{2} \bar{D}$ line towards the larger value of $\bar{D}$. Especially when the value of becomes larger than $3 \sim 4 \mathrm{~mm}$, the value of $\sigma$ begins to decrease. This tendency is also seen in the case of the computed distribution under the stochaseic model taking in the effect of sedimentation. Since the distribution curve resulted in a quite flatter shape near the cloud base as described in the previous paper, $\bar{D}$ and $\sigma$ become larger than 4.5 $\mathrm{mm}$ and smaller than $1 \mathrm{~mm}$, respectively, as shown in Fig. 12 (b) by symbols $\times$. This means that the large raindrops become abundant in the air, and the rainfall represented by such $(\bar{D}, \sigma)$ region may be a heavy rain. The affixed numbers to the symbols show the height level in the cloud.

On the other hand, in the cases of the previous paper where the size distribution did not attain to the stationary distribution, the points of $(\bar{D}, \sigma)$ locate near $\sigma=\frac{1}{2} \bar{D}$ line, as shown by symbols and $\bigcirc$. The case shown by the black circles is caused due to that the effects of drop coalescence and breakup are not vigorous. And in another case shown by the white circles, that the value of $\bar{D}$ can not be larger than $3.5 \mathrm{~mm}$ is caused by the less effect of sedimentation due to the strong downdraft.

Thus it is supposed that the concentration of liquid water content to the drop of median volume diameter may be caused by the various kinds of physical effect such as sedimentation, coalescence and breakup of drops. This may be related to physical explanation for the reason why liquid water content of drops distributes in the form of normal distribution. The discussion and consideration on this problem will be made in future.

\section{Summary}

The drop-size distributions of the various types of precipitation were studied from the view of share of liquid water content of drops. Most of them seemed to obey the truncated normal 


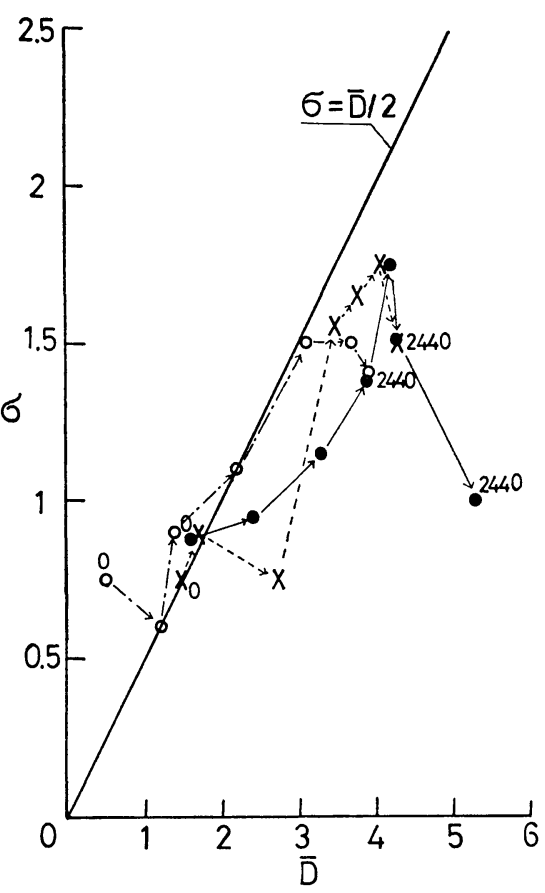

(a)

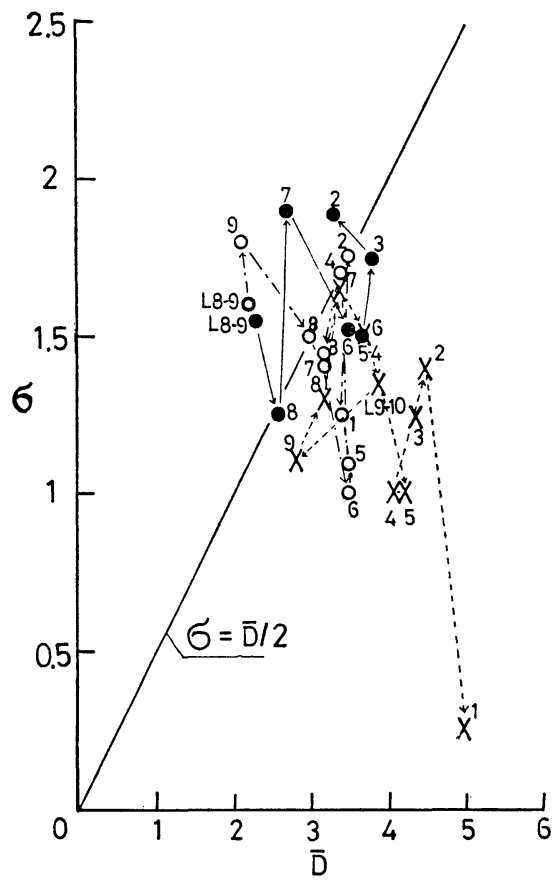

(b)

Fig. 12. Some examples of $\sigma-\bar{D}$ relation.

(a) Time change of $(\bar{D}, \sigma)$ point of the normalized distributions for the computed distributions as obtained in Fig. 11 in the writer's previous paper. The symbols of, $\bigcirc, \times$ and $\bigcirc$ are for the case of (a), (b) and (c) of Fig. 11 of the previous paper, respectively. The affixed numbers of 0 and 2440 indicate the time of beginning of computation and the time at $2440 \mathrm{sec}$ after then, respectively. The plots between them represent each stage of every $400 \mathrm{sec}$.

(b) Altitude change of $(\bar{D}, \sigma)$ point of the normalized distributions for the computed distributions as obtained in Fig. 12 (plotted by O), Fig. 14 (a) (plotted by $\times$ ) and Fig. 15 (plotted by $\bigcirc$ ) of the writer's previous paper. The affixed numbers to the symbols in the figure show the height level in the cloud.

distribution of liquid water with size in the considered range of $0 \sim 7 \mathrm{~mm}$ diameter. The adaptability of the normal distribution for the original one is good, and the derived precipitation parameters are in the region within $\pm 10 \%$ of the obtained parameters from the original distribution.

The usefulness of the newly proposed equation of drop-size distribution as compared with the hitherto equations of Marshall-Palmer, Best, Shiotsuki and Gunn-Marshall may be written as follows. First, the new equation is applicable for almost all kinds of types of the rainfall hitherto observed. Secondly this is expanded to be applicable for another precipitations of snowflake and graupel. Third, the present equation is applicable not only for an average distribution of a precipitation as well as the hitherto proposed equations, but also for a distribution observed in a instantaneous sampling in a precipitation.

For convenience in determination of size distribution, the precipitation parameter diagrams were made. By use of those diagrams, we can easily determine the drop-size distribution by knowing the radar reflectivity, the precipitation rate, and the particle number flux. In fact, the present equation has two parameters of the mean diameter of drops; $\bar{D}$ and the variance from it; $\sigma^{2}$ which seem to be dependent on the type of precipitation corresponding to the growth stage. If the reliable $\sigma-\bar{D}$ relation according to the precipitation type is established in future, the determination of the drop-size distribution is far 
more easily because we have only to know any two of the parameters of $Z, R, M$ and $N$.

In the last section physical consideration on the process to the normal distribution of liquid water content with size were referred little. This is left as future problem.

\section{Acknowledgement}

The writer wishes to thank Prof. C. Magono of Hokkaido University for his steady consideration and advice. The writer also appreciates the careful reading and many valuable comments on this paper by referees. The computations were performed by the FACOM $230-60$ at the computing center of Hokkaido University.

\section{References}

Best, A. C., 1950: The size distribution of raindrops. Quart. J. Roy. Met. Soc., 76, 16-36.
Fujiwara, M., Yanase, T. and K. Takahashi, 1972: Relationships between radar reflectivity $Z$ and the rainfall intensity $R$ on snowflake and graupel. Tenki. 19, 31-36. (In Japanese)

Gunn, R., and G. G. Kinzer. 1949: The terminal velocity of fall for water droplets in stagnant air. J. Met., 6, 243-248.

Gunn, K. L. S., and J. S. Marshall, 1958: The distribution with size of aggregate snowflakes. J. Met., 15, 452-461.

Imai, I., 1964: A Fitting equation for raindrop-size distributions in various weather situations. Proc. 11 th Weather Radar Conf., 149-152.

Marshall, J. S., and W. Mck. Palmer, 1948: The distribution of raindrops with size. J. Met., 5, 165-166.

Shiotsuki, Y., 1974: On the flat size distribution of drops from convective rainclouds. J. Met. Soc. Japan. 52, 42-60.

\title{
含水量の正規分布で表現した降水粒子の粒度分布
}

\author{
塩 月 善 晴 \\ (山口大学工業短期大学部)
}

これ迄報告された種々の粒度分布式について, ある直径区間内に入る雨滴, 雪片及び霞の融解滴の占める含水量の 分布を調べると，分布は正規分布によって近似することができた．前に報告した九州での観測及び数值実験で見られ る平坦な粒度分布に対しても同様な結果が得られた。 新らしく得られた分布によって計算される各種の降水パラメー タ $Z$ (レーダ反射因子), $R$ (降水強度), $M$ (含水量) などは実際の粒度分布より得られる値の $\pm 10 \%$ 以内にあり, 新分布式は実用的には十分な粒度分布式となりうる。

新粒度分布式は粒子の平均直径 $\bar{D}$ とその標準偏差 $\sigma$, 及び含水量 $M$ の三つのパラメータをもっている. このう ち $\sigma, \bar{D}$ は降水タイプに依存して拈り，降水タイプ毎に例觉ばパラメータ $R$ でそれぞれ表現できそうであるが，現 在のところ種々の粒度分布に対応する降水タイプの詳しい分類が明らかでない，そこで $R, Z$, 及び $N$ (降水粒子フ ラックス；個ヶの粒子の大きさを知る必要がない）の観測值があれば直ちに $\bar{D}, \sigma, M$ を決定できる方法を示した. 